\title{
Clinical evaluation of the effect of anti-allergic mattress covers in patients with moderate to severe asthma and house dust mite allergy: a randomised double blind placebo controlled study
}

\author{
L H M Rijssenbeek-Nouwens, A J Oosting, M S de Bruin-Weller, I Bregman, \\ J G R de Monchy, D S Postma
}

See end of article for authors' affiliations

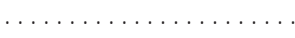

Correspondence to: Dr LH M

Rijssenbeek-N ouwens, $\mathrm{N}$ ederlands A sthma center Davos, Symondstrasse 11 ,

CH 7270 Davos Plat,

Switzerland;

Irijssenbeek@nad.ch

Revised version received 8 April 2002

Accepted for publication 9 April 2002

\begin{abstract}
Background: The use of anti-allergic mattress covers in patients with asthma can result in a large reduction in the level of house dust mite allergen in dust samples. Apart from a reduction in histamine induced bronchial hyperresponsiveness, there are few data on the effect of mattress covers on clinical efficacy and quality of life in patients with moderate to severe asthma.

Methods: Thirty patients with asthma and house dust mite allergy were studied in a randomised, double blind, placebo controlled study. Before and after using anti-allerg ic covers for 1 year, dust was collected from the mattresses to determine concentrations of Dermatophagoides pteronyssinus (Der $p$ 1), and bronchial hyperresponsiveness and quality of life were measured. The patients scored their symptoms (lungs and nose), morning and evening peak flow values, and rescue medication for 14 days before and after the intervention period.

Results: There was a significant reduction in the concentration of Der $p 1$ in the dust collected from the mattresses in the actively treated group after 1 year compared with before treatment; no change was found in the placebo group. In both the actively treated and placebo groups there was no significant improvement in $\mathrm{PC}_{20}$ histamine. Q uality of life improved similarly in both groups. The symptom score of the lower airways did not significantly change in either group. A significant decrease in nasal symptom score was seen in the actively treated group compared with before treatment, but there was no significant difference between the groups. No changes in morning and evening peak flow values, peak flow variability, nor in the use of rescue medication were found in either group.

Conclusion: The use of anti-allergic mattress covers results in significant reductions in Der $p 1$ concentrations in carpet-free bedrooms. However, in patients with moderate to severe asthma, airways hyperresponsiveness and clinical parameters are not affected by this effective allergen avoidance.
\end{abstract}

E xposure and sensitisation to house dust mite (HDM) allergens has been established as an important risk factor for the development of asthma in most parts of the world. ${ }^{1}$ The rate of sensitisation to mite allergens is directly related to its exposure. ${ }^{2}$ The severity of asthma is also related to allergen exposure, ${ }^{3}$ as measured by the level of bronchial hyperresponsiveness, forced expiratory volume in 1 second $\left(\mathrm{FEV}_{1}\right)$, and variability in peak expiratory flow (PEF). The relation between exposure and asthma symptoms in sensitised patients is complex, but asthma is usually more severe in sensitised patients who are exposed to higher allergen levels. ${ }^{3}$ In effectively mite allergen free environments such as hospitals ${ }^{4}$ or high altitude Alpine sanatoria, ${ }^{56}$ the condition of asthma patients improves both symptomatically and in terms of non-specific bronchial responsiveness. These results suggest that avoidance of mite allergen leads to a decrease in airways inflammation with consequent improvement in bronchial hyperresponsiveness and symptoms. It may take many months for the clinical effects to become fully apparent and re-exposure often results in a rapid relapse. ${ }^{7}$ It is therefore essential to achieve and maintain a major reduction in exposure.

Many methods of allergen avoidance have been tested in small intervention studies, but only a few have been subjected to controlled trials. Some show benefit when reduction in allergen exposure can be achieved ${ }^{8}$; others seem to be in effective. ${ }^{10} 11$
Reduction of allergen exposure in the bedroom is the primary target of avoidance measures, since the bed is the most important habitat and source of mite allergens to which we are exposed for many hours during nocturnal sleep. The most effective and probably most important avoidance measure is to cover the mattress, pillows, and duvets with mite allergen impermeable covers. ${ }^{8-10}$ Acaricides have been shown to be ineffective, ${ }^{12}$ time and energy consuming, and they require repeated application. Carpets are also an important microhabitat for mite colonisation and a possible source from which beds can be reinfested, ${ }^{13}$ so this source of mites should also be eliminated. Allergen avoidance measures seem to be more effective in the early stage of the disease. ${ }^{14}$ The effects of allergen avoidance measures in more advanced stages of asthma are not known.

A double blind, placebo controlled study was undertaken to investigate whether allergen impermeable covers as a single intervention are of clinical benefit to patients with moderate to severe asthma. Only non-smoking patients with a smooth bedroom floor whose disease had been stable for the previous 6 months were included. Patients with furry pets were admitted if they had no pet allergy. All had moderate to severe asthma and house dust mite allergy, severe bronchial hyperresponsiveness, and relevant exposure to house dust mite allergens. A study period of 1 year was chosen to exclude seasonal variation in exposure to Der $p 1 .^{15} 16$ 


\section{METHODS}

Patients

Thirty eight patients aged 11-44 years with a history of asthma and house dust mite allergy were recruited from the outpatients department of Asthmacenter Heideheuvel in Hilversum, The Netherlands, from J anuary 1996 to December 1998. Informed consent was obtained from the patients or their parents. The patients were selected on the basis of increased bronchial responsiveness to histamine inhalation $\left(\mathrm{PC}_{20}<4 \mathrm{mg} / \mathrm{ml}, 30\right.$ minute method), positive skin tests and/or raised specific IgE to house dust mite allergen, and relevant HDM exposure on the mattress ( $>1 \mu \mathrm{g}$ Der $\mathrm{p} 1 / \mathrm{g}$ dust). All patients had $\mathrm{FEV}_{1}$ values $>60 \%$ (predicted value). Patients had no history of respiratory tract infections in the previous 6 weeks or severe asthma attacks in the previous 6 months. None had received oral corticosteroids in the previous 6 months.

All patients gave informed consent. The medical ethics committee of Asthmacenter Heideheuvel approved the study.

\section{Study design}

The study was of a randomised, placebo controlled, double blind, parallel group design, comparing the effect of allergen impermeable encasings on the mattresses, pillows and bedcovers during 1 year with matching placebo encasings.

At the start of the study a trained respiratory nurse visited the patients to collect dust samples from the mattresses of the patients for Der p 1 measurement and to note the allergen avoidance measures already present in the house. All patients included in the study had smooth bedroom floors. Patients were instructed to wash their sheets each week at $60^{\circ} \mathrm{C}$. A part from the mattress encasings, no other allergen avoidance measures were taken. At the end of the study the same nurse visited the houses again to collect dust from the mattress covers.

The patients were included during the entire year; the inclusion period was 2 years. Pollen allergic patients were tested outside the pollen season.

At the first visit patients underwent clinical evaluation. $\mathrm{FEV}_{1}$ and vital capacity (VC) values were measured, skin tests performed, and a $\mathrm{PC}_{20}$ histamine was assessed. Medication was withheld before the study period: inhaled steroids and sodium cromoglycate for 1 week before the bronchial histamine provocation test; theophyllines, oral $\beta_{2}$ adrenergic agents, long acting inhaled $\beta_{2}$ adrenergic agents, and antihistamines for 48 hours, and inhaled short acting $\beta_{2}$ adrenergic drugs for 6 hours before the tests.

Collection and extraction of house dust

Before the intervention, at 4 and 8 months, and at the end of the intervention mattress dust was collected by the same vacuum cleaner (Philips Vitall 377, 1300 watt, Philips, Eindhoven, The Netherlands) from the whole mattress during 2 minutes with a special filter device (ALK, Horsholm, Denmark). At the start of the study dust was collected directly from the mattresses; at the end of the study dust was collected on top of the encasings. The filters were stored in the freezer at $-20^{\circ} \mathrm{C}$ until analysis at the end of the study.

Der p 1 antigen was measured using enzyme linked immunosorbent assay (ELISA). Monoclonal antibodies against Der $p 1$ were immobilised on a 96-well plate. Incubation with the dust extracts was followed by a second incubation step with a polyclonal antibody (horseradish peroxidase, $\mathrm{HRP}$ ). After adding 1,2-phenyldiamine $\mathrm{HCl}$ (OPD) as substrate, absorption at $490 \mathrm{~nm}$ was measured using an ELISA reader.

Histamine challenge

Histamine phosphate solutions (doubling concentrations from 0.25 to $32 \mathrm{mg} / \mathrm{ml}$ ) were administered through a De Vilbiss 646 nebuliser with a gauged output of $0.13 \mathrm{mg} / \mathrm{ml}$. The

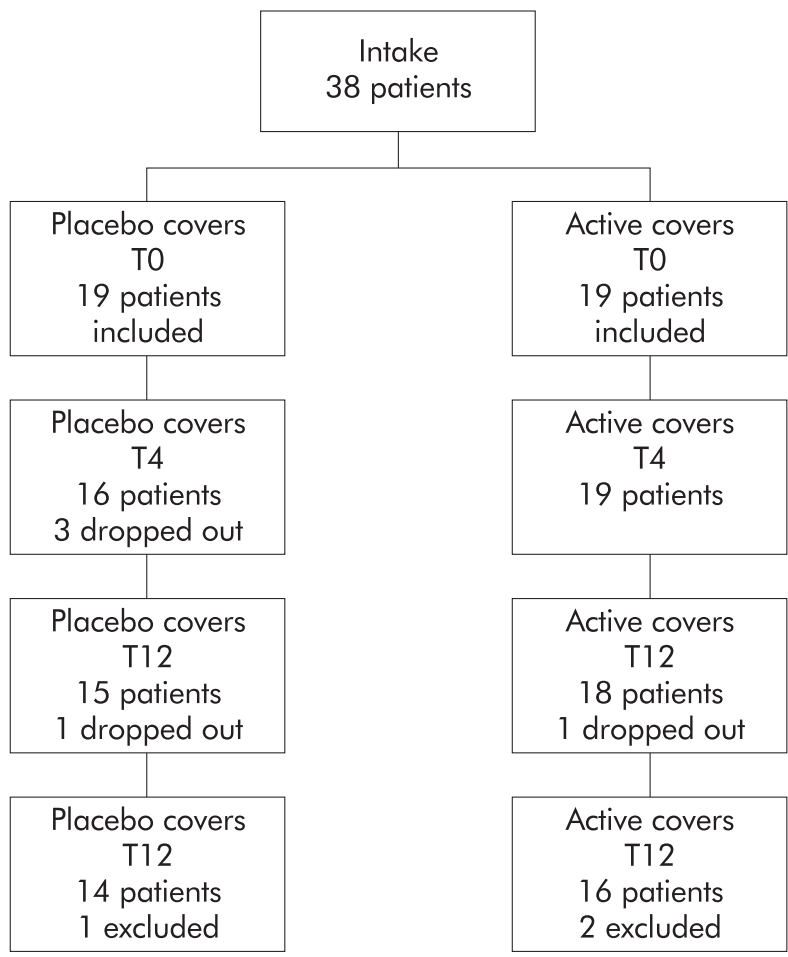

Figure 1 Trial diagram: T0 =baseline, T4 = 4 months, $\mathrm{T} 12=12$ months.

nebuliser was mounted on a valve box with an aerosol filter. The nebulisation time was 30 seconds, during which the patient was instructed to breath quietly. The test was started with inhalation of a phosphate buffer aerosol. Before inhalation three measurements of $V C$ and $F V_{1}$ were performed ( $J$ aeger $M$ asterscreen). FEV $\mathrm{F}_{1}$ was measured after each concentration. $\mathrm{PC}_{20}$ histamine was derived by linear interpolation.

Mattress encasings

$M$ attresses, pillows, and bedding in the intervention group were encased with covers supplied by Cara C'air (Allergy Control AC btm Velserbroek, Netherlands). The matched placebo covers were made by the same company. The encasings were placed in position by a research nurseand left in situ for 1 year.

Quality of life

Quality of life was assessed by the Quality of Life for Respiratory IIIness Questionnaire (QoL-RIQ). ${ }^{17}$ The QoL-RIQ is a disease specific quality of life questionnaire for patients with asthma and COPD which consists of 55 items divided into seven domains: breathing problems ( 9 items), physical problems ( 9 items), emotions ( 9 items), situations triggering/ enhancing breathing problems ( 7 items), general activities (4 items), daily and domestic activities (10 items), social activities, relationships and sexuality ( 7 items). To focus the questions on the patients' experiences, items are formulated in terms of "how much trouble" they had experienced from the mentioned symptom or emotion. In the case of activity related items, questions are stated in terms of "how much they were impeded" by their disorder in carrying out that specific activity. Patients are asked to give their answer on a 70 point Likert scale ranging from "not at all" to "extremely" troubled or impeded. Reliability (test-retest, internal consistency) and validity have been proven. ${ }^{17}$

Clinical parameters

During the 14 day period before the intervention and at the end of the 12 month intervention period the patients were 


\begin{tabular}{|c|c|c|c|c|c|c|c|c|}
\hline Patient & Age & Sex & $\begin{array}{l}\mathrm{FEV}_{\text {( }}(\% \\
\text { pred) }\end{array}$ & $\begin{array}{l}\mathrm{PC}_{20} \text { hist } \\
(\mathrm{mg} / \mathrm{ml})\end{array}$ & Skin test* & Rhinitis & $\begin{array}{l}\text { Medication } \\
\text { asthma }\end{array}$ & $\begin{array}{l}\text { Medication } \\
\text { rhinitis }\end{array}$ \\
\hline \multicolumn{9}{|c|}{ Placebo group } \\
\hline 1 & 21 & M & 97 & 1.76 & 2.1 & - & $B, S B$ & - \\
\hline 2 & 11 & M & 79 & 0.74 & 1.1 & + & $\mathrm{B}, \mathrm{SB}$ & - \\
\hline 3 & 11 & M & 97 & 4.00 & 1.4 & + & $B, S B$ & - \\
\hline 4 & 29 & M & 81 & 0.33 & 1.2 & - & $F, S M$ & - \\
\hline 5 & 21 & M & 73 & 2.43 & 2.0 & + & $B, S B$ & B \\
\hline 6 & 27 & $\mathrm{~F}$ & 70 & 0.90 & 1.2 & + & $B, S B$ & B \\
\hline 7 & 44 & M & 70 & 1.89 & 1.2 & + & F, SM & $\mathrm{F}$ \\
\hline 8 & 17 & $\mathrm{~F}$ & 138 & 1.78 & 1.9 & + & - & B \\
\hline 9 & 40 & M & 64 & 1.13 & 1.6 & + & $B, S B$ & - \\
\hline 10 & 29 & M & 103 & 0.71 & 1.5 & + & - & - \\
\hline 11 & 28 & $\mathrm{~F}$ & 73 & 0.45 & 2.2 & - & $F, S B$ & - \\
\hline 12 & 12 & M & 106 & 4.00 & 1.6 & + & B, SB & - \\
\hline 13 & 25 & $\mathrm{~F}$ & 98 & 1.53 & 1.5 & + & SB & - \\
\hline 14 & 30 & M & 100 & 2.90 & 1.5 & - & $B, S B$ & - \\
\hline Mean & 25 & & 89 & 1.75 & 1.6 & & & \\
\hline SD & 10 & & 20 & 1.21 & 0.4 & & & \\
\hline \multicolumn{9}{|c|}{ Active group } \\
\hline 1 & 25 & $\mathrm{~F}$ & 99 & 1.19 & 1.5 & + & $B, S B$ & - \\
\hline 2 & 29 & M & 99 & 0.95 & 1.6 & - & B & - \\
\hline 3 & 41 & M & 67 & 3.79 & 2.2 & + & $\mathrm{B}, \mathrm{SB}$ & - \\
\hline 4 & 24 & $\mathrm{~F}$ & 86 & 2.00 & 1.8 & + & $B, S B$ & - \\
\hline 5 & 31 & M & 81 & 1.22 & 1.5 & - & - & - \\
\hline 6 & 24 & M & 80 & 0.55 & 1.1 & + & $B, S B$ & B \\
\hline 7 & 22 & $\mathrm{~F}$ & 104 & 2.67 & 1.4 & + & B & - \\
\hline 8 & 51 & $\mathrm{~F}$ & 70 & 0.45 & 1.2 & + & $B, S B$ & B \\
\hline 9 & 32 & M & 68 & 0.42 & 1.1 & - & B, SM & - \\
\hline 10 & 36 & $\mathrm{~F}$ & 103 & 0.35 & 1.8 & + & SB & B \\
\hline 11 & 42 & M & 75 & 0.42 & 1.2 & - & B, SM & - \\
\hline 12 & 18 & $\mathrm{~F}$ & 103 & 2.35 & 1.2 & + & $\mathrm{F}, \mathrm{SM}$ & $\mathrm{F}$ \\
\hline 13 & 40 & $\mathrm{~F}$ & 98 & 0.86 & 1.6 & + & $B, S B$ & B \\
\hline 14 & 30 & $\mathrm{~F}$ & 107 & 1.16 & 1.9 & + & $F, S B$ & $\mathrm{~F}$ \\
\hline 15 & 41 & $\mathrm{~F}$ & 97 & 0.98 & 1.1 & - & B, SM & - \\
\hline 16 & 37 & M & 76 & 0.91 & 1.3 & - & $S B$ & - \\
\hline Mean & 33 & & 88 & 1.27 & 1.5 & & & \\
\hline SD & 9 & & 14 & 0.97 & 0.3 & & & \\
\hline
\end{tabular}

* X times histamine reaction.

$\mathrm{B}=$ beclomethasone or budesonide; $\mathrm{F}=$ fluticasone; $\mathrm{SB}=$ sa lbutamol; $\mathrm{SM}=$ salmeterol; $\mathrm{FO}=$ =formeterol.

asked to keep diary cards in which asthma and nasal symptoms, peak flow values, and medication use were recorded twice daily. Asthma symptoms included dyspnoea, cough, expectoration, and wheezing. Nasal symptoms included nasal blockage, rhinorrhoea, sneezing, and itching. Each item was scored on a scale from 0 (no symptoms) to 4 (severe symptoms).

The patients were trained in performing peak flow manoeuvres with the mini-Wright meter. They were instructed to perform three readings and to record the highest value in the morning when waking and in the evening before sleeping.

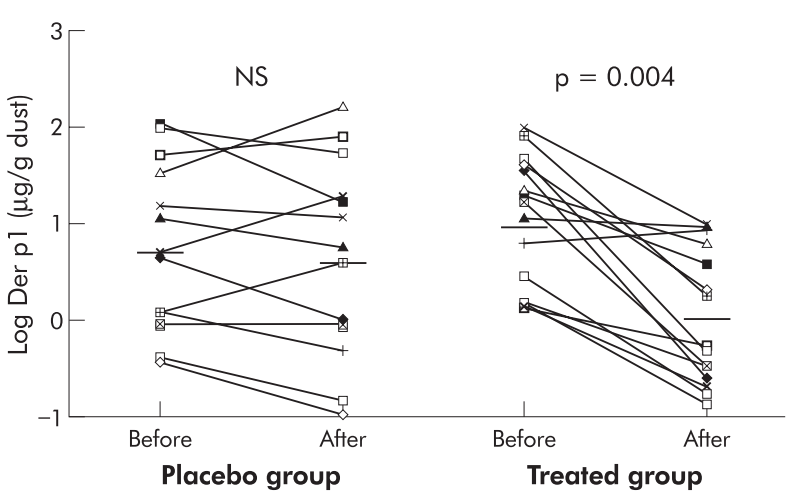

Figure 2 Log values of mean Der $p 1$ levels ( $\mu \mathrm{g} / \mathrm{g}$ dust) before and after 1 year of intervention (treated: $0.97 \vee 0.03$; placebo: $0.73 \mathrm{v}$ $0.61)$.
Patients were asked to continue their normal inhalation medication and to record extra rescue medication in case they needed it.

Data analysis

Statistical analyses were performed with SPSS. Comparisons within groups (before and after intervention) were made with the Wilcoxon signed rank test. Logarithmic data were analysed using the sign test. The Mann-Whitney $U$ test was used for between group comparisons. $p$ values of $<0.05$ were

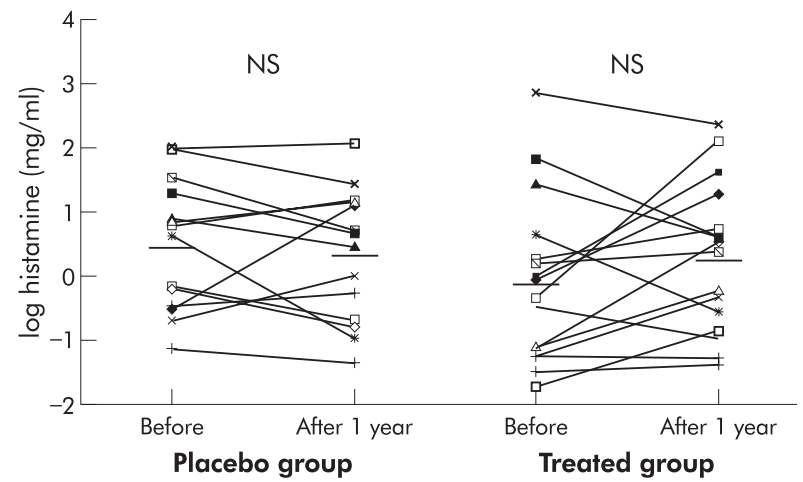

Figure 3 Logarithmic $\mathrm{PC}_{20}$ histamine values before and after 1 year of intervention (treated: $-0.11 \vee 0.28 \mathrm{mg} / \mathrm{ml}$; placebo: $0.48 \mathrm{v}$ $0.33 \mathrm{mg} / \mathrm{ml})$. The geometric mean values of the groups are represented by horizontal lines. 


\begin{tabular}{|c|c|c|c|c|c|}
\hline \multicolumn{3}{|c|}{ Placebo group } & \multicolumn{3}{|c|}{ Treated group } \\
\hline Patient & Before & After & Patient & Before & After \\
\hline \multicolumn{6}{|c|}{ Pulmonary symptoms } \\
\hline 1 & 1.50 & 0.21 & 1 & 2.71 & 0.42 \\
\hline 2 & 1.33 & 5.20 & 2 & 0.64 & 3.00 \\
\hline 3 & 1.07 & 3.14 & 3 & 3.30 & 5.85 \\
\hline 4 & 0.92 & 0.00 & 4 & 2.14 & 1.30 \\
\hline 5 & 2.38 & 4.78 & 5 & 0.07 & 0.00 \\
\hline 6 & 6.38 & 0.43 & 6 & 2.00 & 1.64 \\
\hline 7 & 2.00 & 0.28 & 7 & 1.14 & 1.50 \\
\hline 8 & 8.35 & 10.92 & 8 & 8.25 & 7.07 \\
\hline 9 & 0.14 & 0.21 & 9 & 3.14 & 2.78 \\
\hline 10 & 0.21 & 0.21 & 10 & 0.92 & 0.35 \\
\hline 11 & 1.21 & 0.14 & 11 & 0.00 & 1.25 \\
\hline 12 & 4.33 & 3.50 & 12 & 2.42 & 5.28 \\
\hline 13 & 0.75 & 4.14 & 13 & 4.00 & 4.09 \\
\hline \multirow[t]{3}{*}{14} & 0.00 & 0.00 & 14 & 2.07 & 1.42 \\
\hline & & & 15 & 0.00 & 0.00 \\
\hline & & & 16 & 0.00 & 0.00 \\
\hline Median & 1.27 & 0.36 & & 2.04 & 1.46 \\
\hline Range & $(00-8.35)$ & $(00-10.92)$ & & $(00-8.25)$ & $(00-7.07)$ \\
\hline \multicolumn{6}{|c|}{$\mathrm{N}$ asal symptoms } \\
\hline 1 & 1.71 & 0.86 & 1 & 4.57 & 2.42 \\
\hline 2 & 2.14 & 4.00 & 2 & 3.21 & 2.16 \\
\hline 3 & 2.50 & 5.70 & 3 & 2.30 & 4.28 \\
\hline 4 & 0.00 & 0.00 & 4 & 2.50 & 0.10 \\
\hline 5 & 5.00 & 2.50 & 5 & 1.42 & 0.57 \\
\hline 6 & 5.23 & 4.71 & 6 & 0.64 & 0.50 \\
\hline 7 & 1.00 & 0.00 & 7 & 6.57 & 5.21 \\
\hline 8 & 7.64 & 10.92 & 8 & 5.00 & 4.07 \\
\hline 9 & 0.35 & 0.71 & 9 & 1.92 & 2.00 \\
\hline 10 & 0.64 & 0.28 & 10 & 3.23 & 0.50 \\
\hline 11 & 0.14 & 0.00 & 11 & 0.00 & 0.00 \\
\hline 12 & 11.16 & 2.00 & 12 & 1.42 & 1.00 \\
\hline 13 & 2.85 & 2.71 & 13 & 0.16 & 1.00 \\
\hline \multirow[t]{3}{*}{14} & 0.00 & 0.00 & 14 & 0.75 & 0.42 \\
\hline & & & 15 & 0.00 & 0.00 \\
\hline & & & 16 & 0.00 & 0.00 \\
\hline Median & 1.93 & 1.43 & & 1.67 & $0.79 *$ \\
\hline Range & $(00-11.16)$ & $(00-10.92)$ & & $(00-6.57)$ & $(00-5.21)$ \\
\hline
\end{tabular}

considered significant. Values are expressed as mean (SE) or as median (range).

Power calculations were performed. We expected a $20 \%$ increase in the $\mathrm{PC}_{20}$ histamine level. Based on the mean $\mathrm{PC}_{20}$ of the complete group of $1.59(0.38) \mathrm{mg} / \mathrm{ml}$, an increase to 1.91 (0.38) was expected. With a power of $99 \%$ of achieving a significant result at the $5 \%$ level, the calculated sample size was 29.3 patients. As 30 patients completed the study, a $20 \%$ change in $\mathrm{PC}_{20}$ histamine would have a probability of $99 \%$ of being noticed.

\section{RESULTS}

Thirty eight atopic non-smoking patients with asthma and house dust mite allergy entered the study. Eight patients did not finish the study, five from the placebo group and three from the treated group. In the placebo group three dropped out because of asthma instability, one because of moving to another city, and one because the recording of symptoms, peak flow and rescue medication was not sufficient to make an accurate analysis. In the treated group one individual dropped out because the study was too much of a burden, and two because of insufficient diary keeping. Drop out due to disease instability was significantly higher in the placebo group. 30 patients completed the entire study, 16 in the treated group and 14 in the placebo group (fig 1). The clinical characteristics of these patients are presented in table 1.
Although both groups had severe hyperresponsiveness (geometric mean values of $\mathrm{PC}_{20}$ histamine 1.75 and $1.27 \mathrm{mg} / \mathrm{ml}$ in the placebo and treated groups, respectively), three patients in each group did not regularly use inhaled steroids. The demographic characteristics of the two treatment groups were similar (table 1 ). There were no significant differences between the two groups in $\mathrm{PC}_{20}$ histamine, $\mathrm{FEV} \mathrm{V}_{1}, \mathrm{PEF}$, and medication used.

Der $p 1$ concentrations on mattresses

Figure 2 shows mean log Der $p 1$ concentrations on the mattresses before and 12 months after the start of the study in both groups. In the treated group Der $\mathrm{p} 1$ concentrations on the mattresses were significantly lower after 1 year (26.19 (8.58) $\vee 2.79(0.88) \mu \mathrm{g} / \mathrm{g}$ fine dust, $\mathrm{p}=0.004)$. In the placebo group there was no significant reduction in Der $p 1$ (23.28 (10.44) $\vee 25.11$ (11.98) $\mu \mathrm{g} / \mathrm{g}$ fine dust, $\mathrm{p}=0.18$ ). A significant difference in the treatment induced change in Der $p 1$ concentration was seen between the two groups $(p=0.04)$. The significant reduction in the Der $p 1$ concentration was present after 4 months and persisted throughout the year.

Histamine challenge

At the start of the study the mean $\mathrm{PC}_{20}$ histamine was 1.45 $(0.44) \mathrm{mg} / \mathrm{ml}$ and after 1 year this had risen to 1.66 (0.35) $\mathrm{mg} / \mathrm{ml}$ in the treated group; this difference was not significant ( $p=0.64$, fig 3 ). In the placebo group there was no significant change in mean $\mathrm{PC}_{20}$ over 1 year (from 1.75 
Table 3 Peak flow values before and after intervention (median values of 14 days of registration)

\begin{tabular}{|c|c|c|c|c|c|}
\hline \multicolumn{3}{|c|}{ Placebo group } & \multicolumn{3}{|c|}{ Treated group } \\
\hline Patient & Before & After & Patient & Before & After \\
\hline \multicolumn{6}{|c|}{ Morning peak flow } \\
\hline 1 & 581 & 549 & 1 & 365 & 409 \\
\hline 2 & 315 & 240 & 2 & 727 & 740 \\
\hline 3 & 395 & 342 & 3 & 416 & 450 \\
\hline 4 & ND & ND & 4 & 312 & 337 \\
\hline 5 & 467 & 550 & 5 & 619 & 588 \\
\hline 6 & 292 & 336 & 6 & 517 & 501 \\
\hline 7 & 536 & 554 & 7 & 437 & 455 \\
\hline 8 & 520 & 512 & 8 & 319 & 328 \\
\hline 9 & 432 & 416 & 9 & 460 & 437 \\
\hline 10 & 475 & 600 & 10 & 329 & 365 \\
\hline 11 & 370 & 354 & 11 & 398 & 340 \\
\hline 12 & 375 & 347 & 12 & 500 & 480 \\
\hline 13 & 400 & 380 & 13 & 226 & 246 \\
\hline \multirow[t]{3}{*}{14} & 548 & 542 & 14 & 368 & 388 \\
\hline & & & 15 & 476 & 446 \\
\hline & & & 16 & 450 & 444 \\
\hline Median & 432 & 416 & & 426 & 440 \\
\hline Range & $(292-581)$ & $(240-600)$ & & $(226-727)$ & $(246-740)$ \\
\hline \multicolumn{6}{|c|}{ Evening peak flow } \\
\hline 1 & 563 & 553 & 1 & 396 & 406 \\
\hline 2 & 288 & 236 & 2 & 683 & 748 \\
\hline 3 & 434 & 343 & 3 & 516 & 470 \\
\hline 4 & ND & ND & 4 & 346 & 390 \\
\hline 5 & 509 & 565 & 5 & 634 & 601 \\
\hline 6 & 289 & 326 & 6 & 502 & 506 \\
\hline 7 & 534 & 592 & 7 & 444 & 456 \\
\hline 8 & 529 & 516 & 8 & 380 & 374 \\
\hline 9 & 431 & 406 & 9 & 399 & 411 \\
\hline 10 & 625 & 700 & 10 & 370 & 386 \\
\hline 11 & 351 & 362 & 11 & 400 & 351 \\
\hline 12 & 375 & 346 & 12 & 497 & 484 \\
\hline 13 & 380 & 400 & 13 & 225 & 247 \\
\hline \multirow[t]{3}{*}{14} & 556 & 552 & 14 & 362 & 360 \\
\hline & & & 15 & 570 & 485 \\
\hline & & & 16 & 449 & 440 \\
\hline Median & 434 & 406 & & 422 & 425 \\
\hline Range & $(228-625)$ & $(236-700)$ & & $(225-683)$ & $(247-748)$ \\
\hline
\end{tabular}

(0.32) $\mathrm{mg} / \mathrm{ml}$ at the start of the study to $1.57(0.28) \mathrm{mg} / \mathrm{ml}$ after 1 year $(p=0.97))$. Treatment induced changes in $P_{20}$ histamine were not significantly different between the two groups $(p=0.77)$.

\section{Quality of life}

Overall quality of life scores were comparable at baseline in the placebo and in the treated group. The same was true for the subdomains. Clinically relevant improvements (difference $>0.5)^{18}$ were seen in breathing problems, physical problems related to chest problems, triggering/enhancing circumstances, and total score in both the treated and the placebo groups. Although the size of the improvements did not significantly differ between the two groups, improvements within the treated group were significant.

\section{Clinical parameters}

Baseline values of asthma symptom scores showed no significant differences between the groups (table 2). The median pulmonary symptom score did not change significantly over 1 year in either group. There was a significant decrease in the nasal symptom score in the treated group $(p=0.04)$ but not in the placebo group; the difference between the two groups was not significant. Baseline PEF values (morning and evening) were comparable for both groups (table 3 ). No significant changes in morning and evening PEF, peak flow variability, or the use of rescue medication occurred in either group following the 1 year intervention.

\section{DISCUSSION}

This study was performed to investigate the effect of anti-allergic mattress encasings in carpet free bedrooms on Der $p 1$ exposure in the bed and on clinical parameters in patients with moderate to severe asthma with allergy to house dust mite. We found a significant reduction in Der $p 1$ concentration in the dust collected from the mattresses in the actively treated group compared with the placebo group. $\mathrm{PC}_{20}$ histamine did not improve during the 1 year intervention period. Although a significant improvement in nasal symptoms and quality of life was observed only in the actively treated group, we found no significant difference between the placebo and actively treated groups in the change in pulmonary and nasal symptoms, quality of life, peak flow values, and use of rescue medication.

Earlier studies using several different types of mattress encasings have al so shown a reduction in Der $p 1$ exposure on top of the mattress (table 4). . $^{8-10} 19{ }^{20} \mathrm{H}$ owever, other studies did not show a reduction in Der $p 1$ concentrations and, remarkably, the carpets in the bedroom were not removed in these studies. ${ }^{21}{ }^{22}$ We excluded the problem of Der $p 1$ contamination from the floor $^{13}$ by including only patients who had uncarpeted floors in their bedroom. This may have contributed to the fact that we could reach a significant reduction in the actively treated group even though we had higher baseline Der p 1 concentrations than other studies. ${ }^{22}{ }^{23}$ The reduction in allergen concentration was reached after 4 months and remained during the whole study period. 
Table 4 O verview of results and set up of controlled mattress cover studies

\begin{tabular}{|c|c|c|c|c|c|c|c|c|c|c|c|}
\hline \multirow[b]{2}{*}{ Author } & \multicolumn{6}{|c|}{ Study set up } & \multicolumn{5}{|c|}{ Parameters } \\
\hline & $\begin{array}{l}\text { No of } \\
\text { patients }\end{array}$ & Age & Design & $\begin{array}{l}\text { Duration } \\
\text { (weeks) }\end{array}$ & Carpet & Acaricide & Der $p 1$ & $\begin{array}{l}\mathrm{PC}_{20} \\
\text { histamine }\end{array}$ & Symptoms & Peak flow & Medication \\
\hline Sarsfield ${ }^{28}$ & 14 & Children & open c & 52 & - & - & + & ND & + & ND & ND \\
\hline M urray ${ }^{26}$ & 20 & Children & $\mathrm{plc}$ & 4 & - & - & - & + & + & ND & ND \\
\hline W alshaw ${ }^{29}$ & 50 & Adults & $\mathrm{plc}$ & 52 & + & - & + & + & + & ND & ND \\
\hline Gillies ${ }^{23}$ & 24 & Children & open c & 12 & + & - & - & - & - & ND & ND \\
\hline Ehnert $^{8}$ & 24 & Children & open C & 52 & + & + & + & + & ND & ND & ND \\
\hline M arks 22 & 35 & Adults & rc & 26 & + & + & - & - & - & - & ND \\
\hline W eeks ${ }^{20}$ & 56 & Children & $r \mathrm{db} p l$ & 24 & + & + & + & ND & ND & ND & ND \\
\hline Carswell ${ }^{19}$ & 70 & Children & $r d b p l$ & 24 & + & + & + & - & ND & - & ND \\
\hline van der Heide ${ }^{9}$ & 59 & Adults & open c & 52 & + & + & + & + & ND & ND & ND \\
\hline Frederick $^{10}$ & 31 & Children & r sb pl & 12 & + & - & + & - & - & - & - \\
\hline van der Heide ${ }^{9}$ & 45 & Adults & open C & 26 & + & - & + & - & ND & ND & ND \\
\hline Cloosterman ${ }^{14}$ & 29 & Adults & r sb pl & 6 & + & + & ND & ND & + & - & ND \\
\hline Sporik ${ }^{21}$ & 85 & Children & open c & 78 & + & + & - & ND & ND & ND & ND \\
\hline Cloosterman ${ }^{11}$ & 157 & Adults & $\mathrm{rdb} \mathrm{pl}$ & 20 & + & + & + & - & - & - & ND \\
\hline
\end{tabular}

open $\mathrm{c}=$ open controlled; $\mathrm{pl} \mathrm{c}=$ placebo controlled; $\mathrm{r} c=$ randomised controlled; $r \mathrm{db}$ pl=randomised double blind placebo controlled; $r$ sb $\mathrm{pl=randomized}$ single blind placebo controlled; N D=not done; +=significant change; -=not significant change.

Although Der $\mathrm{p} 1$ concentrations were significantly reduced in the actively treated group compared with the placebo group, we did not find a significant reduction in bronchial hyperresponsiveness. Other studies have also failed to demonstrate an improvement in bronchial hyperresponsiveness. ${ }^{10} 1122$ Two studies $^{22} 23$ did not find a substantial reduction in allergen concentrations in dust, which explains the lack of improvement in bronchial hyperresponsiveness. Frederick \& $\mathrm{al}^{10}$ stated that all patients were reasonably controlled on regular prophylactic treatment, so little or no change in clinical parameters could be expected. Even Cloosterman and coworkers, ${ }^{11}$ who tried to avoid this treatment effect by including only patients who either did not use inhaled steroids or were able to stop them, did not find a significant improvement in bronchial hyperresponsiveness nor in any of the clinical parameters used such as symptom score, PEF variability, and reversibility of $\mathrm{FEV}_{1}$.

How can we reconcile these observations? Patients participating in our study had severe hyperresponsiveness despite relatively high doses of inhaled corticosteroids of $>800 \mu \mathrm{g}$ (for comparison, $\mathrm{PC}_{20}<4 \mathrm{mg} / \mathrm{ml}$ using the 30 minute method is comparable to $1 \mathrm{mg} / \mathrm{ml}$ in the 2 minute method). Thus, despite suppression of airway inflammation by use of inhaled steroids for years, severe hyperresponsiveness remained. Airway inflammation and bronchial hyperresponsiveness are induced by repeated inhalation of low doses of allergen. ${ }^{24}$ However, a 1 year reduction in exposure to HDM might be too short in patients with a life time exposure before the intervention. One can hypothesise that the persistence of severe hyperresponsiveness is related to airway remodelling, the structural changes in bronchial architecture as a result of chronic airways inflammation..$^{25}$ No further improvement can therefore be expected with allergen reduction that most probably affects acute inflammation in this stage of already established disease.

Until now there have been no data available on the effect of allergen avoidance measures on quality of life. Clinically relevant improvements in quality of life were found in both groups. The instrument we used is a questionnaire specific for asthma and COPD. Our study focused on the allergic component of asthma which was represented by only three of the 55 items. This may partially explain the lack of difference between the two groups. Alternatively, allergen reduction may not affect quality of life, and the improvement in both the intervention and placebo groups may reflect the special attention received by the patient during the study period.

The important question in allergen avoidance studies is whether the avoidance technique used improves asthma con- trol in sensitised patients. ${ }^{27}$ Only a few double blind placebo controlled studies on allergen avoidance in relation to symptoms have been performed (table 4). When reviewing these studies it is clear that improvement in symptoms occurred in four studies. ${ }^{14242628}$ Two studied children, ${ }^{2628}$ one studied patients with mild asthma, and one studied allergic patients who had not yet developed asthma (subclinical). Other studies, ${ }^{112}{ }^{22}$ even in children, ${ }^{1023}$ did not find a reduction in symptoms. PEF was recorded in seven studies; in two a significant increase in PEF occurred in patients with mild and preclinical asthma ${ }^{14} 29$ while in five there was no significant increase in PEF. ${ }^{10} 12192223$ Medication was recorded in one study without a positive result. ${ }^{10}$ Taken together, the data suggest that the contribution of allergen avoidance measures is ineffective in patients with moderate to severe asthma. The severity of the clinical manifestation is influenced by more factors such as other allergens, viruses and air pollution, which are not influenced by the avoidance measures.

Surprisingly, there are no published reports of controlled trials of the effects of allergen avoidance on nasal symptoms. In our study rhinitis symptoms were scored in addition to asthma symptoms and we found a significant improvement in nasal symptoms in the treated group, although the difference between the two groups was not significant. The nose therefore seems to be more responsive to avoidance measures than the lower airways. A controlled trial of avoidance measures in patients with rhinitis using subjective and objective parameters might be of interest.

In conclusion, the use of anti-allergic mattress covers results in a reduction in Der $p 1$ concentrations in carpet-free bedrooms. In patients with moderate to severe asthma no change occurred in airways hyperresponsiveness and clinical parameters. This lack of effect may be due to the chronic stage of the asthma and/or limiting the avoidance measures to the bedroom. Future studies should explore whether night time and daytime avoidance measures in the early stages of the disease are more effective.

\section{Authors' affiliations}

L H M Rijssenbeek-Nouwens, A J Oosting, M S de Bruin-Weller, I Bregman, J G R de Monchy, A sthmacenter Heideheuvel, Hilversum, The $\mathrm{N}$ etherlands

A J Oosting, M S de Bruin-Weller, Department of Dermatology/

Allergy, University of Utrecht, The $\mathrm{N}$ etherlands

D S Postma, Department of Pulmonology, University of G roningen, The $\mathrm{N}$ etherlands

J G R de Monchy, Department of Allergy, University of G roningen, The $\mathrm{N}$ etherlands

This study was supported by the Dutch Asthma Foundation. 


\section{REFEREN CES}

1 Custovic A, Simpson A, Chapman M, et al. Allergen avoidance in the treatment of asthma and atopic disorders. Thorax 1998:53:63-72.

2 Kuehr J, Frischer T, M einert R, et al. M ite allergen exposure is a risk factor for the incidence of specific sensitization. J Allergy Clin Immunol 1994;94:44-52.

3 Custovic A, Taggart S, Francis $\mathrm{H}$, et al. Exposure to house dust mite allergens and the clinical activity of asthma. J Allergy Clin Immunol 1996;98:64-72

4 Platts-Mills T, Tovey E, M itchell E, et al. Reduction of bronchial hyperreactivity following prolonged allergen avoidance. Lancet $1982 ; 675-8$

5 Peroni $D$, Boner $A$, Vallone $G$, et al. Effective allergen avoidance at high altitude reduces allergen-induced bronchial hyperresponsiveness. Am J Respir Crit Care Med 1994;149:1442-6

6 van Velzen E, van den Bos JW, Benckhuijsen JAW, et al. Effect of allergen avoidance at high altitude on direct and indirect bronchial hyperresponsiveness and markers of inflammation in children with allergic asthma. Thorax 1996;51:582-4.

7 Valetta EA, Comis A, Del Col G, et al. Peak expiratory flow variation and bronchial hyperresponsiveness in asthmatic children durng periods of antigen avoidance and reexposure. Allergy 1995;50:366-9.

8 Ehnert B, Lau-Schadendorf S, W eber A, et al. Reducing domestic exposure to dust mite allergen reduces bronchial hyperreactivity in sensitive children with asthma. J Allergy Clin Immunol 1992;90:135-8.

9 Van der Heide S, Kauffman H, Dubois A, et al. Allergen-avoidance measures in homes of house-dust-mite allergic asthmatic patients: effects of acaricides and mattress encasings. Allergy 1997:52:921-7.

10 Frederick J, W arner J, Jessop W, et al. Effect of a bed covering system in children with asthma and house dust mite hypersensitivity. Eur Respir J 1997;10:361-6

11 Cloosterman SGM, Schermer TRJ, Bijl-H ofland ID, et al. Effects of house dust mite avoidance measures on Der $\mathrm{p} 1$ concentations and clinical condition of mild adult house dust mite -allergic patients, using no inhaled steroids. Clin Exp Allergy 1999;29:1336-46.

12 Kalra S, Crank P, Hepworth J, et al. Domestic house dust mite allergen (Der p 1) concentrations after treatment with solidified benzyl benzoate (Acarosan) or liquid nitrogen. Thorax 1993:48:10-4.

13 Custovic A, G reen R, Smith $A$, et al. N ew mattresses: how fast do they become significant source of exposure to house dust mite allergens? Clin Exp Allergy 1996;26:1243-5.

14 Cloosterman SGM, Hofland ID, Lukassen HGM , et al. House dust mite avoidance measures improve peak flow and symptoms in patients with allergy but without asthma: a posible delay in clinical asthma? J Allergy Clin Immunol 1997;100:313-9.
15 Van der Heide S, de M onchy J, de Vries K, et al. Seasonal variation in airway hyperresponsiveness and natural exposure to house dust mite allergens in patients with asthma. J Allergy Clin Immunol 1994;93:470-5

16 Kuehr J, Frischer T, Karmaus $\mathrm{W}$, et al. $\mathrm{N}$ atural variation in mite antigen density in house dust and relationship to residential factors. Clin Exp Allergy 1994;24:229-37.

17 Maillé AR, Koning CJM, Zwinderman AH, et al. The development of the $\mathrm{Q}$ uality of Life for Respiratory Illness $\mathrm{Q}$ uestionnaire $(\mathrm{Q}$ oL-RIQ $)$ : a disease specific quality of life questionnaire for patients with mild to moderate chronic non-specific lung disease. Respir Med 1997;91:297-309.

18 Smeele IJ M, Jacobs JE, Schayck Van CP, et al. Q ua lity of life in patients with asthma and CO PD in general practice; impairments and correlations with clinical condition. Eur J Pract 1998;4:121-5.

19 Carswell F, Birmingham K, O liver J, et al. The respiratory effects of reduction of mite allergen in the bedrooms of asthmatic children: a double blind controlled trial. Clin Exp Allergy 1996;26:386-96.

20 Weeks J, O liver J, Birmingham K, et al. A combined approach to reduce mite allergen in the bedroom. Clin Exp Allergy 1995;25:1179-83.

21 Sporik R, Hill D, Thompson P, et al. The Melbourne House Dust Mite Study: long-term efficacy of house dust mite reduction strategies. J Allergy Clin Immunol 1998;101:451-6.

22 Marks G, Tovey E, G reen W, et al. House dust mite allergen avoidance: a randomized controlled trial of surface chemical treatment and encasement of bedding. Clin Exp Allergy 1994;24:1078-83.

23 Gillies DRN, Littlewood JM, Sarsfield JK. Controlled trial of house dust mite avoidance in children with mild to moderate asthma. Clin Allergy 1987;17:105-11.

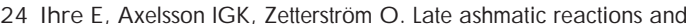
bronchial variability after challenge with low doses of allergen. Clin Allergy 1988;18:557-67.

25 Bousquet J, Yssel H, Vignola AM, et al. $\mathrm{N}$ ew developments in the immunology of asthma with focus on mechanisms and treatment. Curr 0 pin Pulm M ed 1997:3:42-50.

26 Murray A, Ferguson A. Dustree bedrooms in the treatment of asthmatic children with house dust or dust mite allergy: a controlled trial. Pediatrics $1983 ; 71: 418-22$

27 Custovic A, Simpson A, Chapman M D, et al. Allergen avoidance in treatment of asthma and atopic disorders. Thorax 1998;53:63-72.

28 Sarsfield J, Gowland G, Toy R, et al. Mite sensitive asthma of childhood. Trial of avoidance measure. Arch Dis Child 1974;49:716-21.

29 Walshaw $M$, Evans $C$. Allergen avoidance in house dust mite sensitive adult asthma. Q J Med 1986;58:199-215. 